\title{
Thermal Annealing Induced Relaxation of Compressive Strain in Porous GaN Structures
}

\author{
Ahmed B. Slimane, Adel Najar, Tien K. Ng, and Boon S. Ooi ${ }^{*}$ \\ Photonics Laboratory, King Abdullah University of Science \& Technology (KAUST), \\ Thuwal 23955-6900, Kingdom of Saudi Arabia (KSA) \\ *email: boon.ooi@kaust.edu.sa
}

\begin{abstract}
The effect of annealing on strain relaxation in porous GaN fabricated using electroless chemical etching is presented. The Raman shift of $1 \mathrm{~cm}^{-1}$ in phonon frequency of annealed porous $\mathrm{GaN}$ with respect to asgrown GaN corresponds to a relaxation of compressive strain by $0.41 \pm 0.04 \mathrm{GPa}$. The strain relief promises a marked reduction in threading dislocation for subsequent epitaxial growth.
\end{abstract}

\section{INTRODUCTION}

Wide bandgap group III-nitride semiconductors are generally grown on sapphire or $\mathrm{SiC}$ substrates. The large lattice and thermal mismatch between these substrates and the overgrown III-nitride epitaxy resulted in a high dislocations density in the overgrown layer [1]. In addition, despite a partial strain relaxation after the GaN buffer layer growth on sapphire [2], significant residual strain and dislocation density remain in the epitaxy grown subsequently. This motivates the development of porous $\mathrm{GaN}$ structure for strain and dislocation management during epitaxial growth [3]. To our knowledge there is no report on strain relief resulting from annealing of porous GaN. Enhancing the strain reduction by thermal annealing requires further attention, and hence motivates this investigation. The objective of this work is to study the effect of wet etching and annealing strain reduction on bulk GaN. The morphological and optical properties of the porous $\mathrm{GaN}$ and annealed porous $\mathrm{GaN}$ were investigated.

\section{EXPERIMENT}

In this study, the unintentionally doped n-type GaN film was grown on c-axis (0001) sapphire substrate with a resistivity $<$ $0.05 \Omega . \mathrm{cm}$. The thickness of the GaN film was about $30 \mu \mathrm{m}$, and the carrier concentration of the film was $3.4 \times 10^{17} \mathrm{~cm}^{-3}$. Narrow stripes of $10 \mathrm{~nm}$ thick Pt were deposited on the GaN samples. The samples were then etched in the $\mathrm{HF}: \mathrm{CH}_{3} \mathrm{OH}: \mathrm{H}_{2} \mathrm{O}_{2}$ (2:1:2) solution under UV illumination [4]. To study the annealing effect, the samples were heated using the rapid thermal annealing (RTA) process at $400{ }^{\circ} \mathrm{C}, 600{ }^{\circ} \mathrm{C}$ and $800^{\circ} \mathrm{C}$ in nitrogen ambient and atmospheric pressure.

\section{RESULTS AND DISCUSSION}

Figure 1 shows a typical plan-view scanning electron microscopy (SEM) image of porous GaN sample (without annealing). The average pore size is $\sim 30 \mathrm{~nm}$ and elongated features with a size $\sim 100 \mathrm{~nm}$. In the following, we present the investigations on the strain relaxation in the porous $\mathrm{GaN}$ using Raman spectroscopy.

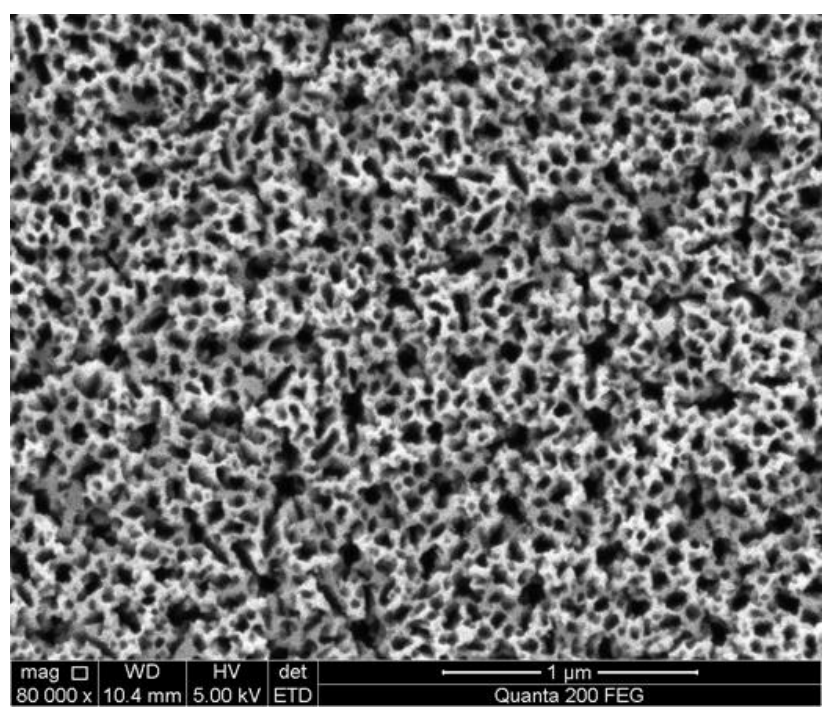

Fig. 1 SEM image for the porous $\mathrm{GaN}$ sample prepared using the electroless chemical etching technique.

Since GaN has a smaller in-plane lattice constant compared to the sapphire substrate, as well as a large thermal expansion coefficient we expect the as-grown $\mathrm{GaN}$ to experience residual biaxial or in-plane compressive strain $\left(\varepsilon_{x x}=\varepsilon_{y y}\right)$ [5]. Figure 2 shows the Raman spectra of the GaN samples. We will focus on the $E_{2}$ high peak phonon frequencies, typical frequencies influenced by the biaxial strain. It is noted that Oh et al. [6] have reported a strain free $\mathrm{GaN}_{2}$ high peak at $567.7 \mathrm{~cm}^{-1}$. The as-grown $\mathrm{GaN}$ has an $\mathrm{E}_{2}$ high peak at 570.0 $\mathrm{cm}^{-1}$. It exhibits a blue shift of about $2.3 \mathrm{~cm}^{-1}$ with reference to the strain free value indicating a residual compressive strain. As for, the porous sample showed an $E_{2}$ high peak close to $\sim 569.5 \mathrm{~cm}^{-1}$. Compared to the as-grown, the porous sample shows a $\sim 0.5 \mathrm{~cm}^{-1}$ red-shift towards the strain free frequencies. It can be deducted that the porous $\mathrm{GaN}$ is reducing the biaxial strain as expected.

In the following we calculate the biaxial strain $\varepsilon_{x x}$ using the linear approximation of the phonon frequency shift $\Delta \omega$ reported by Wagner et al. [7]:

$$
\Delta \omega=K \varepsilon_{x x}
$$


The linear strain shift coefficient $\mathrm{K}$ can be used to calculate the strain from the Raman shift. We adopted the strain shift coefficient value of $2.4 \mathrm{~cm}^{-1} \mathrm{GPa}^{-1}$ reported by Wagner. In the as-grown the residual strain is estimated to be $0.91 \mathrm{GPa}$, whereas for the etched sample the residual strain is around $0.7 \mathrm{GPa}$.

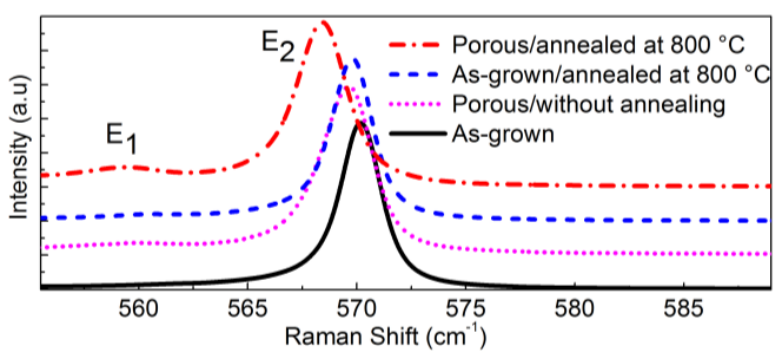

Fig. 2 Raman spectra for the as-grown sample, porous $\mathrm{GaN}$, annealed asgrown $\mathrm{GaN}$ at $800{ }^{\circ} \mathrm{C}$, and annealed porous $\mathrm{GaN}$ at $800{ }^{\circ} \mathrm{C}$ etched for 90 min.

We further investigated the annealing effect on biaxial strain in GaN using Raman spectroscopy. As expected, the annealing of the as-grown GaN reduces the biaxial strain. In fact, the $\mathrm{E}_{2}$ high peak of the annealed samples at $400{ }^{\circ} \mathrm{C}, 600$ ${ }^{\circ} \mathrm{C}$ and $800{ }^{\circ} \mathrm{C}$ all shifted around $\sim 569.4 \mathrm{~cm}^{-1}$. Thus using the linear strain coefficient, the residual compressive strain is around $0.7 \mathrm{GPa}$ for the annealed samples. We attributed this effect to the increase in the a-plane lattice constant.

For the annealing of the porous $\mathrm{GaN}$ prepared using wet etching, we combined the benefits of electroless chemical etching and RTA, we observed a Raman $\mathrm{E}_{2}$ high peak shift to $569 \mathrm{~cm}^{-1}$. The phonon frequency difference between the annealed porous $\mathrm{GaN}$ and the strain free $\mathrm{GaN}\left(567.7 \mathrm{~cm}^{-1}\right)$ increased to $\sim 1.3 \mathrm{~cm}^{-1}$, corresponds to a reduction in compressive strain of $\sim 0.5 \mathrm{GPa}$. It is noted that, compared to the as-grown $\mathrm{GaN}$, the annealed porous $\mathrm{GaN}$ experienced a red-shift in the phonon frequency peak of $\sim 1 \mathrm{~cm}^{-1}$, this shif is higher than the one experienced after $\mathrm{GaN}$ etching $\left(0.5 \mathrm{~cm}^{-1}\right)$, as-grown $\mathrm{GaN}$ annealing $\left(0.6 \mathrm{~cm}^{-1}\right)$ and the annealed porous $\mathrm{GaN}$ reported by Hartano et al. [8]. Thus we conclude that the annealing of porous $\mathrm{GaN}$ leads to a higher biaxial strain relaxation.

The reason for the limited residual strain relieve in the asgrown bulk GaN after RTA is due to the thermal mismatch between sapphire substrate and bulk GaN. In the case of porous $\mathrm{GaN}$, the nanostructure has more room to retain its lattice constant after wet etching and annealing as there are less lateral or sidewall lattice compliances/restrictions. Hence, porous GaN can retain a lower strain condition after RTA compared to the bulk GaN, as evident in our Raman results.

\section{CONCLUSION}

In summary, $E_{2}$-high peak Raman shift was observed in both annealed bulk $\mathrm{GaN}$ and porous $\mathrm{GaN}$, attributed to biaxial compressive strain relief. We demonstrated that the strain relief is more pronounced in porous $\mathrm{GaN}$ with subsequent RTA process at $600{ }^{\circ} \mathrm{C}$ and $800{ }^{\circ} \mathrm{C}$. This approach is effective in strain-relieving the GaN-sapphire template substrate before the subsequent epitaxy growth.

\section{ACKNOWLEDGMENT}

We gratefully acknowledge the Advanced Nanofabrication, Imaging and Characterization (ANIC) Laboratory, KAUST for equipment usage.

\section{REFERENCES}

[1] S. C. Jain, M. Willander, J. Narayan, and R. Van Overstraeten, J. Appl. Phys., 87, 965 (2000).

[2] H. Morkoç, S. Strite, G. B. Gao, M. E. Lin, B. Sverdlov, and M. Burns, J. Appl. Phys., 76, 1363-1378 (1994).

[3] C. Lin, G. Yu, X. Wang, M. Cao, H. Lu, H. Gong, M. Qi, and A. Li, Mat. Lett., 63, 943-945 (2009).

[4] X. J. Xie, F. Zhong, K. Qiu, G. F. Liu, Z. J. Yin, Y. Q. Wang, X. H. Li, C. J. Ji, Q. F. Han, J. R. Chen, and X. C. Cao, Chin. Phys. Lett., 23, 1619 (2006).

[5] T. Kozawa, T. Kachi, H. Kano, H. Nagase, N. Koide, and K. Manabe, J. Appl. Phys., 77, 4389 (1995).

[6] T. S. Oh, H. Jeong, T. H. Seo, Y. S. Lee, A. H. Park, H. Kim, K. J. Lee, and E. K. Suh, J. Appl. Phys., 49, 111001 (2010).

[7] J. M. Wagner and F. Bechstedt, Appl. Phys. Lett., 77, 346 (2000).

[8] H. Hartono, C. B. Soh, S. Y. Chow, S. J. Chua, and E. A. Fitzgerald, Appl. Phys. Lett., 90, 171917 (2007). 